\title{
What Is Nature? On the Use of Poetry in Philosophy Courses for Science Students
}

\author{
HUB ZWART \\ Radboud University Nijmegen
}

Abstract: Please provide an abstract of not more than 150 words.

\section{Introduction}

Since 2000, I have taught philosophy courses for science students from various backgrounds (physics, chemistry, biology, mathematics, informatics, etc.) and at various levels (bachelor's, master's, Ph.D.). In one of these courses, I invite participants to express their understanding of nature in a poem. Although students tend to appreciate this exercise, the objective has never been to make my course more "entertaining," or something like that. Rather, my assignment builds on the conviction that there is a basic, longstanding affinity between philosophy and poetry. Indeed, once upon a time, philosophers tended to communicate their views of nature in verse. Since Socrates, Plato and Aristotle, mainstream philosophy has preferred logic and deductive reasoning over poetry, but the latter never completely vanished from philosophical discourse. The question of this article therefore is whether and in what way the use of poetry as a genre may allow students to deepen their understanding of nature. In other words, to what extent will participants be able to articulate their conceptions of nature more fully and eloquently through poetry than, for instance, by developing a definition?

The design of this paper is as follows. First of all, I will present an outline of the course: a two-day module that is part of an international master's program (section 1). Subsequently, I will show how philosophy and poetry have successfully collaborated in the past. Notably, a particular subset of thinkers, known as "physicists" or "atomists" (from Heraclitus and Empedocles up to Lucretius), exemplify this 
connection, as "philosopher-poets" (section 2). In section 3 I will focus on what is perhaps the highlight of classical philosophical poetry, namely De Rerum Natura by the Roman poet Lucretius, a follower of Epicures. Why does he use poetry, and the typical "tools" of poetry, such as imaginative language, analogies and metaphors, in support of his Epicurean, atomistic views? Finally, I present and assess a selection of poems written by students in the context of my course in order to address the question already raised above: to what extent and in what way may verse-writing enable science students to come to terms with their (implicit) understanding of nature?

\section{Teaching Philosophy to Science Students: A Case Study}

There are basically two ways of teaching philosophy to science students. One option is to start from philosophy (from Plato and Aristotle up to, say, Popper and Kuhn) and present student audiences with the ideas and conjectures of these "great thinkers," these "authoritative voices," concerning scientific inquiry: the top-down approach. Another option is to trawl the archives of science (of present and past) searching for philosophical quandaries, moral collisions and paradigm shifts, for intriguing case studies that contain important lessons for science students of today: the bottom-up approach. Various intermediate forms (combinations of both approaches) are possible of course. I myself tend to opt for the bottom-up approach, since it involves dialogue with and proximity to science. It is in the folds and margins of scientific discourse that some of the most challenging philosophical issues of today emerge. I regard this approach as mutual learning, moreover: probing philosophical issues through trans-disciplinary dialogue and team work.

An important objective of this type of education is to bridge the so-called science-humanities divide, also known as the "two cultures" theorem, advocated by C. P. Snow (1959) and others. In my teachings, I highlight examples of fruitful collaboration and dialogue between science and philosophy, but also between scientists and artists (novelists, playwrights, painters, composers and poets). And this of course includes the work of authors who performed in genres on both sides of the divide (a remarkably large number of modern scientists wrote or even published poetry, for instance, from Goethe up to Erwin Schrödinger). I see science on the one hand and poetry, music, and art on the other as complementary sources of knowledge and insight concerning nature. A "comparative epistemology" may reveal the strengths and weaknesses of scientific and artistic approaches to studying plants, animals, microbes, landscapes or ecosystems (Zwart 2008).

One of my teaching activities, and the course which actually serves as "case study" for this article, is a two-day philosophy module which 
I present once a year in the context of an international master's programme called Transnational Ecosystem-based Water Management, a collaborative effort of the Universities of Nijmegen (the Netherlands) and Duisburg-Essen (Germany). The course enrolls students from various countries worldwide (about thirty students each year), coming from a broad variety of scientific disciplines (ecology, geography, plant biology, sustainability studies, and so on). As a philosophy teacher, I am interested in the students' own views of nature and therefore I set up the module in such a way that it allows them to explore, articulate, and critically assess their own tacit ideas.

The design of the module (after a round of introduction) is as follows: (1) an introductory lecture on the question "What is nature?"; (2) a reading assignment, focusing on a particular case study; (3) a group discussion; (4) the final assignment, involving two tasks (to be carried out in groups of three students); and finally (5) plenary presentations of the results, followed by assessments and discussions. I will now outline these five components somewhat in more detail.

My introductory lecture (step 1) focusses on a question which, for many centuries, has figured quite prominently on the agenda of philosophy, namely "What is nature?" Right at the beginning, I usually ask whether the participants have ever been asked this question before during their university training. Their responses usually indicate that, as a rule, students of the natural sciences, although understanding "nature" is strictly speaking the ultimate objective of their research fields, are hardly ever invited to consider this question at all. Apparently, this is typically a question for philosophers to address. For the latter, things are quite different, of course. The question "What is nature?" is the primordial question of (Western) philosophy, its Ur-Frage as it were.

For indeed, the first treatises on philosophy ever written in Western culture were devoted to nature. Around 475 B.C., Parmenides of Elea wrote a treatise entitled $\mathrm{P} \in \rho \iota$ $\phi v ́ \sigma \in O S$ ("On nature"). Heraclitus ("the Obscure") of Ephesus (535-c. 475 B.C.) wrote his own version, but bearing exactly the same title $(\mathrm{P} \in \rho \iota$ фú $\sigma \in O S)$. Eventually, a whole series of publications by Anaximander (611-547 B.C.), Empedocles (495-435 B.C.), Anaxagoras (c.500-428 B.C.), and Epicurus (341-271 B.C.) followed, under the same heading, so that "On nature" became the title of a whole genre. Building on his predecessors, Aristotle (384-322 B.C.), in his Physics (Aristoteles 1980), finally coined his own, highly influential definition of nature: $\phi v ́ \sigma \iota s$ is that which emerges, comes forward on its own accord, that which has its own inherent principles of change, which is simply "there," without our doing. Like all definitions of nature, Aristotle's version has given rise to a plethora of controversies, notably because it introduces an ontological divide between the natural (produced by nature) and the artificial (produced by 
us), thereby setting aside human beings (or, more general: humanity, technology, and culture) from the rest of nature. Finally, I point out that the debate on nature has never been settled for good and I briefly indicate how, in modern history, a broad variety of (at times quite incompatible) views and definitions of nature (neo-Aristotelian as well as post- or anti-Aristotelian) have emerged: views on nature associated with Christianity, Enlightenment, Romanticism, Darwinism, and so on.

Subsequently, I invite the students to read a paper that focusses on a particular case study (step 2), namely the history of the Dutch landscape, a "mnemoscape" (Zwart 2003) in which Christian, Enlightened, and Romantic views of nature all have left their marks and traces. Over the centuries, this landscape has experienced a number of drastic transformations, notably due to dike building, land reclamation and other technology-based interventions. Currently, we witness a new and slightly paradoxical chapter in this history, namely the "return of the repressed," i.e., the development of "new nature": a type of landscape that allegedly mimics, as closely as possible, the Dutch landscape as it was first described by the Romans two millennia ago. Whereas in other courses of the master's program the focus is on the scientific, technological, and management dimensions, in our module we look at the history of Dutch water management through the magnifying glass of poetry and art. Rather than biochemical analyses of water samples, we study poems and paintings that convey particular views and values concerning the landscape types under discussion.

Thus, I try to show how landscapes and waterscapes, at various stages in history, up to the present, reflect and materialize their inhabitants' basic attitudes towards nature. These attitudes become tangible and visible, not only through hydrotechnologies and science-based nature management policies, but also through various forms of writing, such as poetry and novels. All these materials provide sources of information for a comparative analysis of the way in which the Dutch have shaped and transformed their natural environment, and vice versa (Zwart 2003). It exemplifies what was referred to above as a bottomup approach. Rather than studying and comparing definitions proposed by "Great Thinkers" (philosophers), the module studies how our views and understandings of nature actually become visible, "materialize" as it were, in our concrete interactions with the environment, up to this day. Landscapes and landscape management policies provide intriguing sources of information concerning the ways in which the question "What is nature?" is actually addressed in real life.

Thus, the history of Dutch water management allows us to explore and assess the views and ideals vis-à-vis nature that have left their footprints in landscapes and waterscapes, paying attention to the intriguing history of dikes, polders and wind-mills, focusing not only 


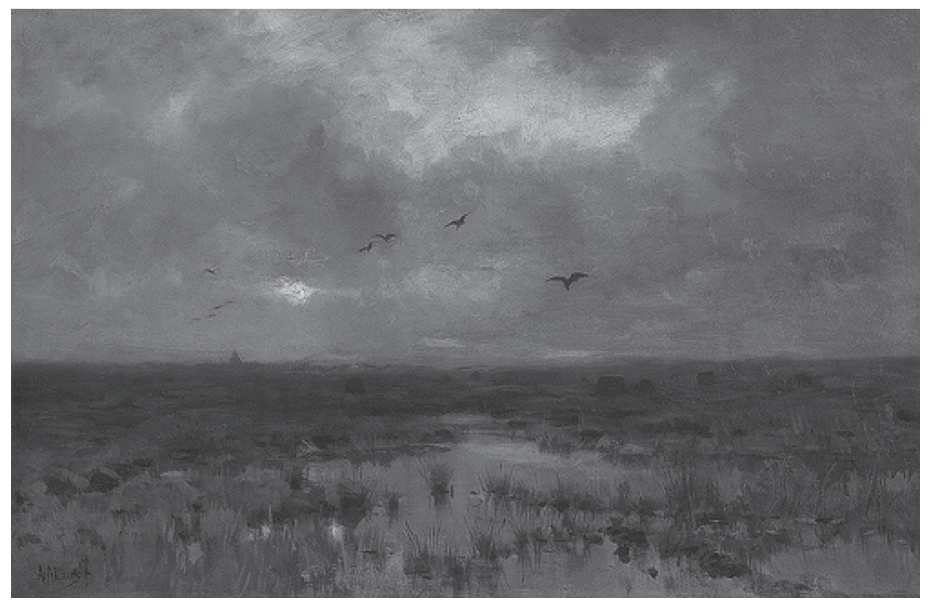

Figure 1: The Marsh (1885), by Anton Mauve

on the role of various techniques and artefacts, but also on the role of ideologies and value systems (such as Christianity) that have functioned as a source of inspiration and justification for policies of land reclamation for more than a millennium, placing concrete water management efforts in a broader moral and historical perspective.

During the final decades of the nineteenth century, however, a remarkable reversal in the Dutch attitude towards water management began to surface. Painters and poets began to appreciate what was left of natural dune and marsh landscapes. This is notably exemplified by a famous painting by Anton Mauve (the teacher of Vincent van Gogh) called The Marsh (1885). It displays an uncultivated marsh area in all its natural splendour, untamed and sublime, presented as something to be valued and cherished rather than destroyed and reclaimed. During this same period, poets, such as the neo-romantic Herman Gorter, devoted many pages of exquisite poetry to the astonishing beauty of dune landscapes. Thus, these arartists inspired a new ideal that began to counteract the "aquaphobic" policies of the past. Art and poetry provided a complementary source of inspiration and information concerning nature, one that challenged the hydro-technological approaches of previous generations. And although these new ideals were temporarily curbed and subdued in the aftermath of the disastrous 1953 flooding (a dramatic event which revivified a rigorous policy of dike-building and hydropower), during the final decades of the twentieth century "nature" (in the form of marshes and other more or less "natural" land- and waterscapes) was granted much more space again. Thus, the module studies sources (artistic and otherwise) that evoke visions of nature that became embedded in concrete water management policies. During the 
group discussion (step 3), students are invited to compare the Dutch story with views and experiences from elsewhere. ${ }^{1}$

In the context of these deliberations, a famous Dutch poem is discussed, namely Thinking of Holland, written by the poet Hendrik Marsman in $1936 .{ }^{2}$ It became something of a national anthem. In fact, during a plebiscite organised in the year 2000, this poem was elected as the best Dutch poem of the twentieth century. In translation, it goes like this:

Thinking of Holland
I see broad rivers
Moving slowly through
Endless lowlands.
Rows of unthinkably
Thin poplars
Standing as high plumes
On the horizon;
And sunken within
Wonderful space
Farms houses,
Scattered throughout the land.

\author{
Clusters of trees, villages, \\ Cropped towers, \\ Churches and elms \\ In one great association. \\ The air hangs low \\ And the sun is slowly \\ Muffled in a grey \\ Mottled fog. \\ And in all the provinces \\ The voice of the water \\ With its eternal calamities \\ Is feared and heard.
}

Although initially the poem seems to voice a mood of harmony and peacefulness (conveying the idea of an intimate embedding of human-

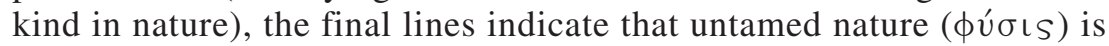
always there, as a looming threat, and will never be silenced completely. Thus, the duality of nature: as a force that fosters, but at the same time threatens, human existence is poetically expressed.

The final assignment (step 4) of the module consists of two fairly challenging tasks, carried out by groups of three students. The first task is to provide a concise but convincing definition of nature (i.e., a comprehensive answer to the question What is nature?). As a rule, this proves difficult for students with a science background. Although (or perhaps because) they are educated as natural scientists (in fields such as plant biology, ecology, geography, and so on) it is difficult for them to define (in a clear and coherent fashion) the overall object of their research, namely "nature." Hardly any of the definitions brought forward by these groups of students tend to survive the critical assessment by the rest of the group during the plenary meeting at the end of Day Two. The inevitable conclusion of this part of the session is that, although we will no doubt continue to use the term, and although the students involved are all expected to study and eventually manage "nature" in a scientific or evidence-based way, the question what "nature" is seems difficult if not impossible to answer via a definition. 
The most challenging hurdle, of course, is how to define the place of human beings (inside or outside?) nature.

The next step is a kind of experiment, an exercise in "comparative epistemology" as it were. If a consistent and conceptually robust definition is so difficult to produce, can perhaps poetry provide an alternative? Will the use of poetry as a genre allow students to deepen their understanding of what nature is?

Thus, the same groups of three students are subsequently asked to write a poem on nature and to present it before a live audience: their fellow students. My experience over the years has quite consistently been that their poems are much better than their definitions, and that their poetry proves much more suitable to capture the tensions and ambiguities that permeate our conceptions of and dealings with nature.

As already indicated, this exercise was never meant to make my philosophy course more popular or entertaining, although this may be a pleasant side-effect. Rather, the idea is that, as we have seen, poetry has played a decisive role in valuating and praising (discovering or acknowledging the aesthetic value of) particular landscape types (such as marshes and dunes), also in the public domain, and will no doubt continue to do so in the f-uture. Furthermore, poetry on the one hand and philosophy of nature on the other have more often worked together in the past. As Frazier and Murray (2009) phrase it: Poetry was at one time the language of philosophy and science par excellence (Frazier and Murray 2009: 62). Twenty-five centuries ago, the first Greek philosophers who turned their thoughts about nature into writing (such as Parmenides and Heraclitus) wrote poetry. They elaborated their philosophy (their understanding of what nature is) in verse. And although mainstream philosophy more or less stopped doing so long ago (a shift in which Plato and Aristotle have played a significant role), it seems legitimate to explore to what extent poetry can again prove a meaningful and rewarding exercise in philosophy courses for science students. Notably because (as I will argue in the next section) many of the poet-philosophers of ancient Greece and Rome were actually "atomists" who believed that material nature was composed of invisible elementary particles. In many ways, the emergence of quantum physics and the molecular turn in the contemporary life sciences can be regarded as a resurge of this atomistic view of nature. Does this imply that there is some room again in science (or at least in the teaching of science and philosophy) for poetry as well? Before presenting some of the results of the course (i.e., nature poetry written by science students), I will first of all briefly review the relationship between atomism and poetry in ancient times. 


\section{A Classic in Science Education: Raphael's School of Athens}

The School of Athens, the famous fresco painted by Raphael in the Apostolic Palace in Rome (between 1510 and 1511), is not only a highlight of Renaissance art, but also a masterpiece of science education, a concise introduction into classical Greek philosophy and science, a sizable early modern "PowerPoint" in paint. In fact, I often use it as a PowerPoint slide during introductory lectures in philosophy, and I am quite sure I am not the only one. On Raphael's masterpiece, all the great intellects of scholarly antiquity (although they actually lived in different places at different times) are gathered under one roof: a huge, Pantheon-like building, reading, deliberating, and-most of alllearning from one another. Two groups of scholars and their students for instance are engaged in mathematical exercises: we see Euclid (author of the famous manual containing the basic "elements" of Greek mathematics) performing geometrical exercises on a wax board before a small audience of students, while to the left Pythagoras is being ostensibly plagiarised. Others (Strabo and Ptolemy) study the globe and the sphere of heaven respectively. We also recognize Socrates, the founding father of logic, thinking with his fingers ("All human beings are mortal," "Socrates is a human being," ergo: "Socrates is mortal"), while Plato and Aristotle occupy the centre of the stage. Plato carries his dialogue Timaeus, which contains a geometric theory of the composition of the cosmos, while Aristotle is holding a copy of his treatise on Ethics, a book that contains a substantial amount of Greek geometry as well. ${ }^{3}$ In short, by most of the scholars assembled here, nature as well as human existence are studied more geometrico. The deductive method, borrowed from ancient Greek mathematics, is regarded as the royal road to knowledge. Rather than $\phi v ́ \sigma \iota s$, Plato preferably used the term кó $\sigma \mu o s$ (cosmos) to present nature as a well-ordered, perfectly structured whole, composed of geometrical elements such as spheres, cubes, pyramids and the like (the subject matter of Timaeus).

Yet, notwithstanding this ambiance of peaceful coexistence and collaboration, some tensions can be discerned as well on Raphael's fresco. Three figures in particular seem to distance themselves from the rest of the group, and from the mainstream debate that is unfolding. They (stubbornly, even disrespectfully) look the other way, engrossed in their own activities and thoughts. These three are Diogenes (who is reading a page), Heraclites (who is writing a poem; we can almost read the verses) and Epicures (who is writing a book). The latter's work was lost in the original, but immortalised by poetry: the long didactic poem De Rerum Natura by Lucretius, which will be discussed in the next session. In other words: Ehat is depicted here can be regarded as an 


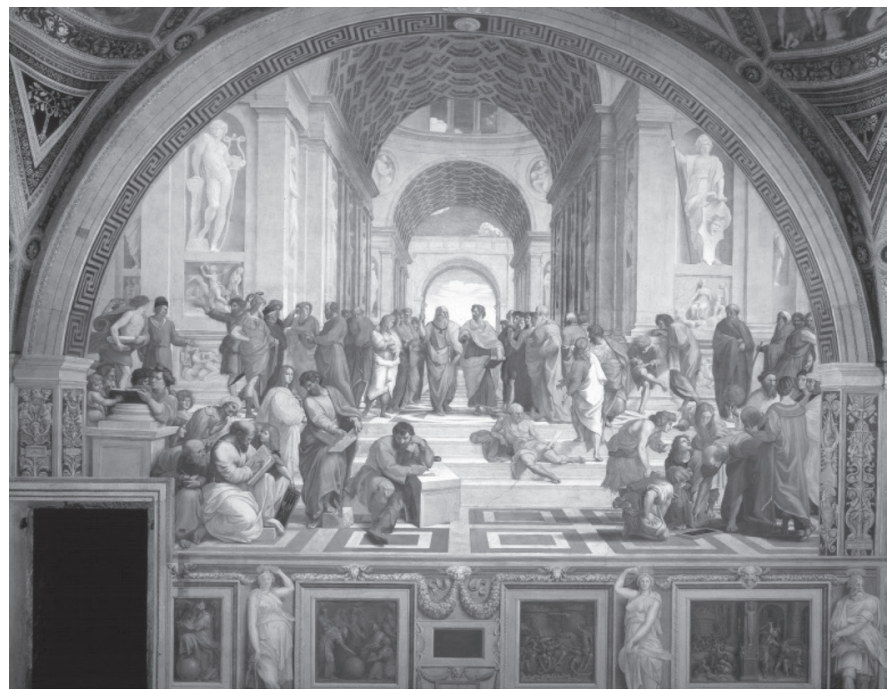

Figure 2: The School of Athens (1510-1511), by Raphael

ancient Greek version of what came to be known as the two cultures theorem. On the one hand, we have rationality, logic, mathematics and astronomy; on the other hand, poetry, thus, two incommensurable ways of coming to terms with nature. This impression is amplified if we consider the styles or strands of thought which Heraclitus and Epicures (the two most peripheral figures in Raphael's fresco) represent. For indeed, they represent a completely different take on nature known as "atomism," quite at odds from the mainstream "academic" Greek philosophy represented by Plato and Aristotle and their schools. Plato and Aristotle see nature as a cosmos, i.e., a perfectly balanced, "Apollonian," harmonious, geometrical order. The atomists' understanding of nature, which Heraclitus and Epicures adhered to, was much more Dionysian. They stressed the fluid, changeable, unpredictable aspects of nature. And to bring this Dionysian dimension of nature to the fore, writing poetry seems much more suitable than constructing deductive logical arguments or performing geometrical exercises. And this is also historically true, as Heraclitus articulated his "obscure" ideas concerning nature in poetry, while the Roman poet Lucretius decided that poetry would be more befitting than prose for presenting the ideas of his beloved atomistic hero Epicures. And this is what Raphael artfully conveys, via the topology of his painting: Heraclitus and Epicures are not only rivals of the academic school. They are absorbed in their own thoughts and writings and looking the other way because they are literally working in a quite different, even juxtaposed direction. They articulate a different conception of nature, and do so by employing a wholly different type of genre: poetry. 
The label "atomists" represents a genealogical line of thinkers such as Heraclitus, Empedocles, Democritus, Epicurus, and others (also known as "physicists"). Notwithstanding various disagreements in terms of details, a family resemblance connects their core ideas. The atomists basically regarded nature and natural entities (including human beings) as composite entities, composed of minute material particles of various shapes, temporarily flocking together and dispersing again in a rather capricious and unpredictable fashion. This view of nature is strikingly captured by a famous line jotted down by Heraclitus: we cannot step in the same river twice. Change, chance, drift, even warfare, are regarded as the core tendencies of all things. Unfortunately, and perhaps not coincidentally, given the level of competition between these ancient schools, while many of the key texts of the mainstream academics (the dialogues of Plato, the lectures of Aristotle, the Elements of Euclid, etc.) have been preserved, the bulk of the writings of the atomists (notably the three-hundred books written by Epicurus, the most radical and prolific protagonist of this line of thought) went extinct. But its core content was nonetheless immortalised in the form of poetry: De Rerum Natura by Lucretius.

\section{De Rerum Natura-A Highlight of Philosophical Poetry}

Our most important source on atomism, and the culmination of the atomistic conception of nature, is the wonderful didactic poem already mentioned, written by Lucretius (99-55 B.C.), during the waning of the Roman republic, entitled The Rerum Natura ("On the nature of things," 1975/1992). It was composed with the explicit purpose of preserving and spreading the ideas of his hero Epicurus, whose legacy was

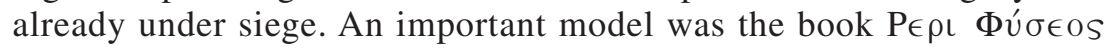
by Empedocles (already mentioned above). As W. H. D. Rouse, his translator, phrases it: "Lucretius undoubtedly looked upon Empedocles as his model as a philosopher-scientist writing in verse: he imitates him several times and expresses his high admiration for him" (Rouse 1975/1992: xlv). De Rerum Natura not only reflects fundamental conceptual differences between the academic and the atomistic school, but also differences in terms of methodology and style. Instead of using deductive reasoning, Lucretius relies on poetry to convey his message. And this implies that, rather than using syllogisms, he uses the "tools" of poetry, such as compelling language, strong visual images and, above all, analogies and metaphors. Indeed, as Rouse argues, the "imperceptibility of the atoms necessitated the employment of numerous analogies from the perceptible world to prove their existence and illustrate their nature and movement" (Rouse 1975/1992: xlv). Therefore, the more 
technical and scientific passages of the poem are especially "rich in metaphor" (Rouse 1975/1992: liv).

I will now give two examples to indicate what this means, taken from the first two Books, in which Lucretius articulates the idea that everything in nature is composed of minute (and therefore invisible) material particles floating, flocking together and dispersing again in the immensity of empty space. In the first section, taken from Book I, he uses an analogy to show that air is composed of elementary particles or atoms. The translation is in prose, but the original is in dactylic hexameters:

There are unseen bodies of wind that sweep the sea, that sweep the earth, sweep the clouds of the sky also, beating them suddenly and catching them up in a hurricane; and they flow and deal devastation in the same way as water, which, soft as it is, suddenly rolls in overwhelming stream when a great deluge of water from the high mountains swells the flood with torrents of rain, dashing together wreckage of forests and whole trees, nor can strong bridges withstand the sudden force of the coming water, with so mighty a force does the river, boiling with rain-torrents, rush against piers; it works devastation with loud uproar and rolls huge rocks under its waves, and sweeps away whatever stands in its path. Thus therefore the blasts of the wind also must be borne along, which, like a strong river, when they have borne down in any direction, thrust all before them and sweep all away with frequent attacks, and at times catch things up in a swirling eddy and whirling them round carry them off in a swift tornado. Therefore I say again and again, there are unseen bodies of wind, since in deed and ways they are found to rival great rivers, which possess a body which can be seen. (I, 277-97)

The image, I think, is quite irresistible. We cannot perceive the atoms of which air is composed, but their cumulative impact is overwhelming. The language is compelling, the images are strong, but the key element is the analogy no doubt. Wind and water are similar in many respects. Winds are like "rivers of air," typically a poet's simile I would say. Although air is less dense than water (and therefore, unlike water, invisible), the fact that air is composed of minute particles (atoms) can clearly be discerned through its impact, which is quite similar to the impact of water. We see how the atoms of the wind are streaming and gliding through the corn fields and the leaves. In the case of a storm, we see that they are forceful enough to destroy trees and houses. Therefore, air and water are essentially similar: They are composed of atoms floating in empty space, continuously changing their direction and pace. To convey this atomistic, Dionysian view of nature, the choice for poetry as a vehicle seems a befitting one indeed.

The second example is taken from Book II, where Lucretius again uses "an image and similitude" (122) to make his point:

[W] henever the sun's rays are let in and pour their light through a dark room: you will see many minute particles [minuta corpora] mingling in many ways 
throughout the void in the light itself of the rays, and as it were in everlasting conflict struggling, fighting, battling in troops without any pause, driven about with frequent meetings and partings; so that you may conjecture from this what it is for the first-beginnings of things [primordia rerum] to be ever tossed about in the great void (II, 114-22).

The section almost reads like a poetic experiment: create a dark room (a "camera obscura"), like Newton did in 1666, and allow a small beam of light to enter. What is usually imperceptible will then become visible. Again, analogies are used. First of all, the elementary particles are compared to particles of dust. The floating of the latter through air comes quite close to how atoms must float and swirl through the void, as envisioned by Lucretius. But then, a second analogy is added, reminiscent of Heraclitus's maxim that all things are not only continuously in flux, but also continuously in strife: the elementary particles are compared to battling troops: captured in an on-going drama of fight and flight, every now and then colliding with one another, forcing one another in various courses and directions, and so on. But in this case, it is a never-ending battle, quite similar to the perennial battle in which waves and rocks are involved in the coastal areas of Greece. Once again, as is usually the case in poetry, in order to convey the message, compelling language, in combination with a number of well-chosen images and analogies, are expected do the work.

In short: the world of ancient Greek philosophy, as depicted on Raphael's famous fresco, was actually an intellectual battlefield (a "Kampfplatz," as Kant (1781/1975) phrases it). Two incommensurable views are struggling with one another: on the one hand the academics, stressing the Apollonian aspects of nature (harmony, order, stability and the like), and on the other hand the atomists, who rather focus on nature's Dionysian dimension. From their perspective, nature emerges as fluid, dynamic, capricious and unpredictable, as a world that is continuously in strife and in flux. These two aspects of nature are brought to the fore with the help of rather dissimilar tools. Whereas the key intellectual activities of academic philosophy are geometry and deductive reasoning, the Dionysian dimension of nature can best be articulated with the help of poetry.

\section{Poem or Definition?}

Let me now turn to the poems written by students following the course. Over the years, more than sixty poems have been written by science students participating in my module. There were no restrictions in terms of form or format (besides the instruction to write poetry, and to do so in English), so that the submitted poems differ in form and style, ranging from very short pieces (a two-line distich was the shortest one) 
up to poems eight stanzas in length, and ranging from sonnets and ballads up to limericks and blank verse. All poems were presented in the form of a PowerPoint slide, read aloud by one of the students, and subsequently discussed with the whole group. As a rule, two or three students were appointed as jury or panel to start the discussion, until others joined in. Criteria for assessing poems were: (a) quality of the language, (b) strength of the images used, (c) concordance between content and form, (d) structure / coherence of the poem, (e) originality.

I will now quote some examples of their work. I have distinguished five subsets of poems (a rudimentary typology) and will present at least one example of each. Here are the subsets:

1. Conceptual poems (poetic definitions-in verse-of what nature $i s$ )

2. Romantic poems (poems in which nature is presented as pristine and sublime, but now polluted, threatened and corrupted by humankind)

3. Sentimental poems (comparing childhood memories of nature with scientific views acquired at the university, in a more or less nostalgic way)

4. Impressionistic poems (presenting concrete experiences of nature, often using blank verse)

5. Engaged poems (poems that criticize contemporary attitudes to nature, as a rule by speaking on behalf of nature: taking nature's point of view. Quite often, these poems are structured as a song text.)

Anonymous examples for every subset will now be presented. I will first quote the poem (or a fragment of the poem, depending on its length) and then briefly comment on it. ${ }^{4}$

\section{Conceptual Poems}

The first subset ("conceptual poems") contains poetry that endeavors to come up with a definition of nature, but now in a poetic manner, such as this one:

Nature is ...

Nature is

Animals and plants

Tropics and steppes

Uplands and lowlands

Rocks and beaches

Everything!

This (unabridged) poem stresses the wholeness and comprehensiveness of nature: nature $=$ everything. Nature's all-encompassing comprehen- 
siveness is emphasized by the word "everything" in the final line, followed by an exclamation mark. The form (an acrostic) $)^{5}$ concords with the content of the poem. All things are seen as segments or components of nature. Like the letters of a word, they add up to a complete unity: nature herself. The sequence of entities mentioned represent "layers" or "levels" of being, moreover. Animals and plants constitute the top layer, with tropics and steppes as their environments, their surroundings. Uplands and lowlands refer to different topological areas, to high and low, until in the next line the coast is finally reached, where "rocks" stand for "high" and "beaches" for "low." The final, primordial, deepest layer is "everything," i.e., nature (or being) as such.

Implicitly, we humans are seen as part of nature too, but wisely the poem does not mention us humans explicitly. That would somehow disturb the poem. It would suggest that, apparently, we are a special case, in need of special attention. We are more or less left out of the picture. This seems to suggest that we are also part of nature, like everything else. But still, the ambiguity of our position stands out, since "we" are at the same time the authors of poems such as this one, the only entities on earth who write poetry about nature, who phrase equations of this type (nature $=$ everything), who think about nature as such. And that is something which plants and animals, let alone steppes, rocks and beaches, will never do. So, if we say "everything," does it really include "us,"-not as a biological species I mean, but as verse-writing animals? This is left undecided.

\title{
Romantic Poems
}

\author{
Nature \\ Frozen leaves \\ Cold and quiet \\ Small but untouched \\ Pure and free \\ Twinkling star \\ Frozen and shiny \\ Brilliantly small \\ Sparks of hope \\ Fossil machines \\ Hot and loud \\ Touch the untouched \\ Destroy the eternal
}

I regard this as an instance of romanticism because nature is represented as balanced and peaceful, unspoiled and pristine, whereas humankind (or rather: human technology) is presented as a major disruptive fac- 
tor. The first two stanzas compare two levels of being, two realms of nature (plants and stars) that in many ways seem to mirror one another. Comparisons between plants and stars can quite often be encountered in romantic poetry, although usually the focus is on the flowers (flower $=$ earthly star, star =heavenly flower) rather than on the leaves, but this may be regarded as the originality of the poem: The frozen leaves seem to reflect the frozen light of the stars. And of course, frost and rime on leaves may glitter and sparkle like stars. Due to this similarity between "nearby" and "far away," "above" and "below," the first two stanzas convey a similar mood: the beauty and tranquillity of nature in all its dimensions, immense and small. And this creates the expectation that the third stanza will be in a similar vein as well. Here, however, a dramatic turn sets in. Technology is presented as a disruptive force, damaging nature, exploiting and disrupting its hidden layers, hidden in eternal darkness, and until recently quite untouched. By not explicitly mentioning humankind, technology ("fossil machines") is presented as an anonymous process, a demonic force beyond our control. All of a sudden, the splendour of nature is endangered by a grim, disruptive event.

\section{Sentimental Poems}

The term "sentimental" is used here not in a pejorative sense, of course, but as a literary style. Some of the poems submitted and presented during the module compare the scientific way of revealing, experiencing and exploring nature with childhood memories. This is an interesting genre notably because childhood memories often play a role as sources of inspiration for choosing a scientific career. (Born 2007) Later in life, the comparison between childhood views and scientific approaches may invoke a sense of loss.

A famous "sentimental" poem in this sense is Edgar Allan Poe's sonnet To science (Poe 1998: 116), from which I will just quote the sextet by way of illustration:

Hast thou not dragged Diana from her car,

And driven the Hamadryad from the wood

To seek a shelter in some happier star?

Hast thou not torn the Naiad from her flood,

The Elfin from the green grass, and from me

The summer dream beneath the tamarind tree?

This is how students articulate the disruptive impact of a scientific education:

\section{Memories of nature}

Leaves crunch under my feet,

Nature's breath cold on my cheek,

A patchwork of colours sown loosely around, 
My mother's voice a reassuring sound.

Relations change over the years,

Colours fade and words appear,

But in these analyses of the mind

Childhood visions are hard to find.

Crunchy leaves and crunchy skin,

Memories become very thin,

Theories, models, numbered things

Do not compare to what childhood brings.

The poem consists of three parts or stanzas, although not separated from one another by blank lines: childhood, contrast, nostalgia. The rhyme is there, but relatively free. The basic message is that the rich and concrete sense impressions of yesteryears (seeing, touching and hearing nature) are more or less erased by scientific theories and tools, by "numbered things," until they become "very thin." But they are brought to life again through poetry. Poems allow us to articulate dimensions of nature eclipsed ("repressed") by science.

\section{Impressionistic Poems}

This type of poetry also presents concrete experiences of nature, but in this case they are not borrowed from childhood memories, but presented as fairly recent. Impressions off the record as it were, experienced during a day of leisure. I will give two examples of this category. The first one reads like this:

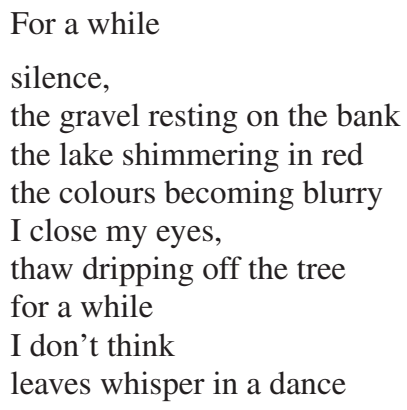

The basic message, as I see it, conveyed by this poem is that we become submerged in nature as soon as we relax, switch off our neocortical reasoning and close our eyes. Allow me to give another example of this subset:

\section{Nature}

Nature is walking through the surf

Watching the sun go down

Something to experience

And hope it will last forever 
Similar to the first example, the poets find themselves in the boundary zone between land and water. This is reminiscent of the ancient Greek experience, namely that the (fleeting, atomistic) essence of nature becomes noticeable where earth, wind and water meet. As soon as we ourselves experience leisure (and indeed, idleness was seen by Greek and Roman authors an important condition for deepening our insight in what nature is), we notice that there is constant mobility in nature. There is, moreover, a contrast between the everlasting mobility of nature (the surf, the sunset) and the temporary mobility of the poets (walking). Sunset is a moment for reflection and nature is experienced as sublime. Typically, experiences such as these are captured in blank verse by students in my course.

\section{Engaged Poems}

The final subset consists of what I regard as "engaged" poetry. This fragment of a much longer poem may stand as an example:

A song

If I were a forest no deforestation;

If I were the air no greenhouse gas emission;

If I were water no waste discharge;

If I were a bird no noise pollution;

If I were a prairie no over-grazing.

If I were the earth, these 'ifs' would come true . . .

One could imagine this to be a folk song, sung by Pete Seeger or a similar troubadour, accompanying himself on a folk guitar. The song clearly has a message. Deforestation and pollution are addressed as environmental problems that result from persistent lack of empathy with nature. The song invites us to put ourselves in nature's place: poetry as a therapy for curing our disruptive blind spots.

\section{Concluding Remarks}

As a rule, scientists (but this also applies to science students) hardly ever seem to question the basic concepts of their field. Usually, they do not ask themselves what "time," "matter," "life" or "nature" is, at least not on a regular basis. It is the objective of a philosophy course to incite students to start doing so. But how to seduce them to "think"? The purpose of this article was to show that poetry can play a role 
in this, notably as an exploratory exercise. By way of conclusion, the following comments can be made:

1. My experience over the years has consistently been that, in comparison, the students' poetry far outstrips their (usually unconvincing, often even fairly "clumsy") definitions, although perhaps it would be wrong to play out both genres against one another. They must no doubt be seen as complementary exercises, and in a more extended course, writing poetry (as an exploratory device) would perhaps help students to find a more convincing and suitable definition later on.

2. Although year after year I tend to be quite impressed by the quality of the lyrics written by these students, poetic quality as such is not the issue. The objective of our course is not to learn students how to write charming verses. What is important is that, apparently (and this is confirmed by student evaluations), composing poetry as a group assignment is a more rewarding exercise (for this group, at this stage) than struggling with definitions.

3. Poetry allows us to articulate a particular dimension of nature, namely nature as that which is fluid, vulnerable, fleeting and transitory. This concords with the atomistic, Heraclitean and Epicurean view of nature: everything is in flux, nothing will last. The "academic" quest for definitions rather seems to concur with a view of nature that stresses stability.

4. In many poems, a shift occurs from "object" to "subject." They often begin with a poetic description of nature, but in the end (in the final stanza so to speak) they often probe and question our own place and role in nature.

5. Perhaps surprisingly, items that may be regarded as typical of science (such as concepts, tools, contrivances, software, special devices, etc.) are hardly ever mentioned by students in their poetry.

6. Some poems convey the conviction that poetry, in comparison to the quantifications, equations and nomenclature of science, speaks a more "natural" language, a language much more in tune with nature herself. But this may be a romantic view on poetry and nature (in line with Schelling's idea that nature is the unconscious poetry of the Mind, 1800/1027).

Allow me to end this paper with a student's poem: 


\section{POETRY IN PHILOSOPHY COURSES FOR SCIENCE STUDENTS}

Where nature ends and we commence

Is very hard to tell

But only we can ask that question

And make it rhyme as well.

\section{Notes}

1. This is an interesting exercise as the course enrolls students not only from other European countries (Germany, Scotland, Spain, etc.), but also from Chile, China and Vietnam.

2. Interestingly, Hendrik Marsman (1899-1940) was actually travelling in the Mediterranean South when he wrote this poem.

3. See for instance: his definition of virtue as the mean between the excessive (the hyperbole) and the deficient (the elliptic); or his account on distributive justice and proportionality.

4. Some poems have been shortened or slightly edited (typos or spelling). Authors have agreed to anonymous publication of their work.

5. The use of an acrostic is not unique. There are more poems in my sample that are (wholly or partly) acrostics, perhaps as an alternative to the use of rhyme.

\section{Bibliography}

Aristoteles. 1980. Aristotle 4: Physics 1-4. The Loeb Classical Library (Cambridge, Mass.: Harvard University Press).

Born, R. van den. 2007. "Thinking Nature: Everyday Philosophy of Nature in the Netherlands. Thesis. Nijmegen: Radboud University Nijmegen.

Frazier W., and K. Murray. 2009. "Science Poetry in Two Voices. Poetry and the Nature of Science." Science Education Review 8:2: 58-78

Heidegger M. 1954. Was heißt Denken? (Tübingen: Niemeyer).

Kant I. 1781/1975. Kritik der reinen Vernunft. Werke in zehn Bänden III. Hrsg. W. Weischedel (Darmstadt: Wissenschaftliche Buchgesellschaft). (English ed.: Critique of Pure Reason, trans. N. Kemp Smith [London: Macmillan, 1958]).

Lucretius. 1975/1992. De Rerum Natura/On the Nature of Things. The Loeb Classical Library (Cambridge, Mass.: Harvard University Press).

Poe, E. A. 1998. Collected Poems (Ann Arbor, Mich.: Lowe \& Hould).

Rouse W. 1975/1992. "Introduction.” In Lucretius 1975/1992: ix-lxv.

Schelling, F. W. J. 1800/1927. System des transcendentalen Idealismus, in Schellings Werke, 2: 349 (III: 349).

Schrödinger E. 1949. Gedichte (Godesberg: Helmut Kupper).

Snow, C. P. 1959. The Two Cultures and the Scientific Revolution (New York: Cambridge University Press).

Zwart H. 2003. "Aquaphobia, Tulipmania, Biophilia: A Moral Geography of the Dutch Landscape." Environmental Values 12:1: 107-28. http://dx.doi.org/10.3197/096327103129341252 .2008. Understanding Nature: Case Studies in Comparative Epistemology (Dordrecht: Springer). http://dx.doi.org/10.1007/978-1-4020-6492-0 


\section{HUB ZWART}

$H u b$ Zwart is professor in the Centre for Society and the Life Sciences at Radboud University Nijmegen. The focus of his research is on the philosophical dimensions of the life sciences, including biomedicine, research with animals, genomics, ecogenomics, and postgenomics (synthetic biology, human enhancement, bio-materials).h.zwart@science.ru.nl 